\title{
Analysis of Present Study for MOOC
}

\author{
Zhongbin Wei ${ }^{1, a^{*}}$ and Miao Shang ${ }^{2, b}$ \\ ${ }^{1,2}$ Mechanical and electrical technology department, Xijing University, Xi'an, China \\ a358825406@qq.com, b445700839@qq.com
}

Keywords: MOOC; Resources platform; Network curriculum; Remote education

\begin{abstract}
MOOC is a big open online course. At present, the development of the MOOC is very rapidly in various countries. MOOC platform is continuously advancing in some colleges and universities. In this article, the MOOC is carried on the simple introduction; MOOC development present situation is analyzed; the origin of the MOOC course platform is described; Classification and characteristics of MOOC is studied; the growth of the MOOC process is described. Finally some views are pointed out, such as the development of the MOOC needs to face the world, the development of the MOOC should consider the interests of the public, and the development of the MOOC must pay attention to practice.
\end{abstract}

\section{Introduction of MOOC}

For class is a large open online courses (hereinafter generally referred to as the MOOC). The abbreviation of massive open online courses is MOOC. Since 2012, the Internet company with online courses as the core. Online courses have emerged and have gained rapid development. Public network teaching platform gathered plenty of free, high-quality international school courses. The public network teaching platform to provide online support for learners. Public network teaching platform including course task arrangement, learning evaluation, the interaction between students and teachers [1].

MOOC provides a teaching platform for the majority of students. MOOC has many advantages:

(1) MOOC different from traditional classroom learning, but study fragmentation, mu imposed a knowledge in the form of the present curriculum, students can make full use of spare time to study.

(2) Based on the online platform, MOOC taken courses can be recycled, teachers are no longer need to be repeated.

(3) Breakthrough the limitation of traditional course of time, space, never leave home can learn many courses in university, abundant learning resources.

(4) Penetration classroom, students are required to have higher self-discipline ability and autonomous learning ability, and finish the online course.

\section{Development Present Situation of MOOC}

MOOC is by the Canadian scholar Dave Cormier and Bryan Alexander professor in 2008. MOOC is the Massive Open Online Courses of English abbreviations. MOOC usually translated as large a online classes or a massive open online courses [2]. MOOC refers to the large scale network courses in this article.

MOOC brings together students interest in learning, experts, or teaching assistants. As long as the basic learning equipment all over the world can register and access to the curriculum resources and curriculum content. They based on the common learning goals and content, using a series of free access to network resources to provide or the content of the materials they need to institute, exchange of learning through social networks. MOOC collaboration space can be across many different platforms and technology. Such as MOOC participants can learn to create their own blog posts, to discuss different aspects of the problem, or weibo, Twitter, etc. Canadian scholar Stephen George Siemens and Downs in 2008 opened Connectivisn and Connective Knowledge courses is considered 
to be the first MOOC courses. This course learners can learn in free. Based on the associated with the course of socialism and the traditional network courses, course not rely on the learning management system of learning resources. Began to show the related topics for this course is Zhou Wei zhong - a communication, learning a week without teachers will provide relevant information. At the same time, it supports the participants use different tools to participate in the study, discussion and evaluation. Siemens and Downs opened PLENK courses. Courses in these characters can be said to be the leading MOOC.

\section{Origin of MOOC Course Platform}

Of course, in order to be able to let learners to normal and orderly to get the related resources, courses required platform arises at the historic moment. Many venture capitalists see business opportunities. Investors and work together to create the course of the world's top university [3]. A tenured professor at Stanford, Sebastian Thrun from a top university in 2011 to give up its lifetime professorship, free sharing of artificial intelligence course on the Internet. For-profit Udacity company was formally established in 2012. Udacity company hopes to cooperate with first-rate professors at the university of top. The company will be science, technology, engineering and mathematics (STEM) of free and open curriculum. Udacity company make students all over the world are able to enjoy the high quality education resources. Aim is to put the education as a fundamental human right [4]. Convenient, affordable and effective higher education should move towards the world. Education is life, education is popular. 14 courses from October 2012 to March 2014, 33 courses, course number is steadily increasing.

With these two course providers profit way different is the third platform EDX, is a common capital injection from MIT and Harvard University was founded in May 2012 [5]. Non-profit EDX best of all is able to provide free this two schools of course, they also welcomed all over the world's top university to join them, for learners to provide high-quality interactive online courses around the world. Originated from the Massachusetts institute of technology, online learning program MITx open-source, edx on the purpose of offering free online courses through the analysis of the learning process data at the same time, the application of research techniques in teaching, explores the application of the composite teaching mode in the network course, provide learners with more chances of receiving \& good teach $\mathrm{ff}$, these results is also open.

\section{Classification and Characteristics of MOOC}

MOOC got rapid development on a global scale. In our country, many colleges and universities also set off a upsurge of learning MOOC MOOC and research. In Sydney institute, Sui Fai John Mak according to the different theoretical basis for the MOOC is divided into five categories, namely teaching socialist MOOC, MOOC of cognitivism, constructivism MOOC, social constructivism of MOOC, and associated MOOC. According to the different emphasis of each MOOC course design, MOOC is divided into a MOOC based on social network, based on task MOOC and MOOC based on content. LisaMXane don't think all the MOOC classification of good and bad points, classification of MOOC no comprehensive and one-sided. The purpose of these courses is not so much in the open network environment of distributed learning course content and skills, rather than learn social skills such as communication [6].

Now has been approved by the classification is based on the associated socialist MOOC and MOOC based on behaviorism [7]. Based on the correlation of socialism MOOC advocates the idea of the participants linked together. Participants through discussion, interactive learning methods so as to obtain personalized knowledge construction and ultimately formed in knowledge network emergent curriculum group learning path. In this kind of MOOC mode, the starting point of learning resources is a teacher. Students learning center was conducted over resources to explore. MOOC supporters, Canadian scholar. Simmons said: "our MOOC model emphasizes innovation, creativity, autonomy, and social networking study. And Coursera model is a more traditional way of learning. The general 
way is video display, quizzes and tests." Marc Bousquet concluded: "the biggest advantages of good MOOC support the active practice of learning. Knowledge production, for example, instead of knowledge consumption."

\section{Growth of MOOC}

The remote education and network education has a history of a certain. A series of large-scale began to put network has more hot topics and platform of discussion. Media, bloggers and experts and mass media have been widely discussed MOOC [8]. Surging MOOC course and people for the improving of the MOOC interest, MOOC has become a hot topic of higher education magazine articles. Similarly, there are also many bloggers in the curriculum leadership, the Angle of the participants and spectators of various views. Academic papers about MOOC also begin to emerge, such as journals, conference proceedings, and professional magazine, and the number increased year by year. This phenomenon is similar to many other technology created the academic community. MOOC course number trend chart as shown in Fig. 1.

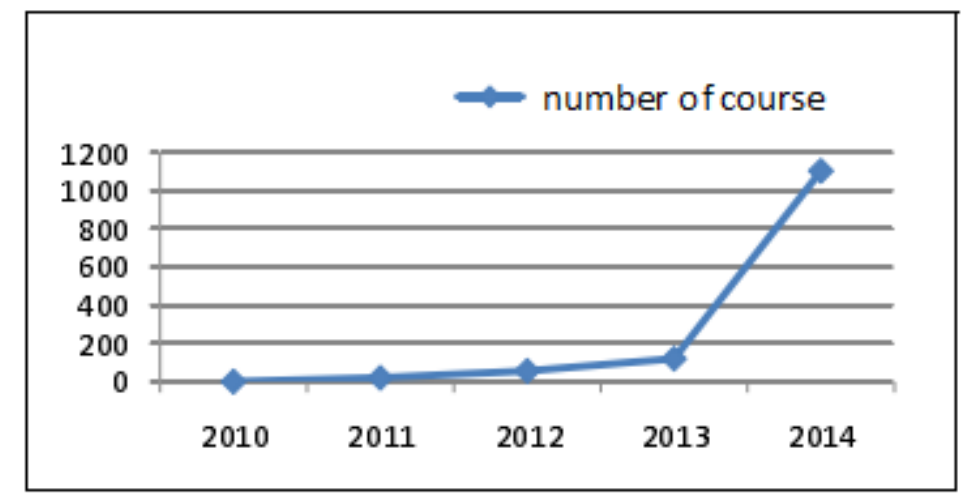

Figure 1. MOOC course number trend chart

To MOOC theoretical discussion may be more. In the MOOC white paper, on the basis of MOOC in the development of the United States and Canada, through academic papers, blogs, media reports and literature review's official website. Writing from the view of the British higher education, for the development of higher education institutions better understand MOOC and trend, provide help for development strategy. The issue of 2013 edition of the China education network in the white paper, scholars pay more attention to the concept and development of MOOC [9]. MOOC of the strong impact of higher education, education scholars or institutions in colleges and universities to discuss should be how to deal with the opportunities and challenges, and its effect for our country's higher education and so on. "Journal of higher education research open MOOC project, from the social nature of education, science, attributes, and attribute analysis in three aspects: the management scholars to the MOOC discussion. In October 2013, the subject of MOOC fourth "BBS" for young scholars of China distance education, the characteristics of the experts and scholars to MOOC, development, application, influence and inspiration and some problems about the development of the localization is discussed. MOOC of historical development, the advantages and challenges. Esposito qualitative research as the emerging online research methods and setting up the emergence and evolution of ethics, moral problems in competition, privacy issues. IT put the future development of education resources and open course, because the public is more concerned with "free" rather than "open", which makes MOOC provider to doubt their own copyright permission [10].

There are also some scholars the study of the technical support needed for learning MOOC. At the university of California, Berkeley, Dorsa Sadigh, Sanjit a. Seshia, Mona Gupta embedded system was put forward to solve because of large-scale learner in MOOC solution creation, automatically determine the grade and the automatic evaluation problem. Li hua and attack skill on MOOC oriented learning management system framework were studied [11]. The framework is based on the original 
LTSA model adding new elements to ensure the data real-time update of learning, such as interaction, and knowledge agent components, to facilitate learners learning network construction.

At present, the development of the MOOC is very rapid, each platform is constantly advancing. In April 2013, Stanford university and edx cooperative development of non-profit open source edx platform development; In May 2013 at Georgia tech team and unique Udacity company launched a master's degree in computer science course; In June 2013, EDX build developer community for its online and blended learning platform; EDX announced in September of 2013 and the Google cooperation on JT - source platform; In October 2013, EDX and French higher education cooperation, create a French online learning portal. EDX announced in March 2014 new members structure, expand the edx.org, which includes universities and various foundation; In March 2014 Udacity launched Uda city device applications.

\section{Conclusions}

Since 2012, the Internet company with online courses as the core. Online courses have emerged and have gained rapid development. Public network teaching platform gathered plenty of free, high-quality international school courses. A MOOC is a big open online courses. At present, the development of the MOOC is very rapidly in various countries. On every platform of MOOC in advance. In this article, the MOOC was carried on the simple introduction; MOOC development present situation were analyzed; the origin of the MOOC course platform was described; Classification and characteristics of MOOC was studied; the growth of the MOOC process was described. Finally, points out that the development of the MOOC need to face the world, the development of the MOOC should consider the interests of the public, the development of the MOOC must pay attention to practice.

\section{References}

[1] L.Yuan, Stephen Powell, H.L.Ma: International Status Quo Analysis of Massive Open Online Courses Closed, Vol. 84 (2013) No. 3.

[2] J.B.Wang, H.T.Yang: New Field of Overseas Investment - New Trend of Transnational Higher Education (DongYue Review, China, 2012)

[3] B.C.Ji:Our Country's Higher Education Scale Forecast Analysis in 2020, Vol. 1 (2011) No. 1, p. 305.

[4] Z.Wang,J.X.Tian: Inheriting Hin for Class in Our Country the Development of the SWOT Analysis, Journal of the new curriculum (below), Vol.7(2013)No.7.

[5] W.X.Cai,J.Wang: The First Year of MOOC, Vol.4(2012),P.16-18.

[6] H.Y.Liu: U DP Proportion Higher Education and Social Policy Research, Vol. (2012), P. 27-28.

[7] Benoit Minogue: Higher Education Spending and Output-Complexity of Relationship, Peking University Education review, Vol. 2 (2013), 60.

[8] Henry m. levin. Education How to Adapt to Future-Background of American Education, Peking University Education Review, Vol. 2 (2013), p. 2-3.

[9] P.Wang: New Development and Application of Large-Scale Online Open Courses, Vol. 19(2013)No.1.

[10] G.P.Feng: Transnational Education - International Comparative Study (Shanghai People's Publishing House, China, 2010)

[11]T.Wang,Q.Li: MOOC - A Giant Open Courses of Unicom Based Model, Vol.19(2013)No.3. 